\title{
CONSERVANDO LA DIVERSIDAD DE LENGUAS
}

\author{
por
}

\author{
H. RUSSEL BERNARD
}

\section{INTRODUCCION}

En 1987, el Sr. Jesús Salinas y yo, concebimos un plan para desarrollar un centro en donde los indígenas de México pudieran aprender a leer y escribir sus propias lenguas mediante la utilización de los microprocesadores. Más importante todavía, pudieran imprimir y editar sus obras en sus respectivas lenguas, sobre cualquier tema que eligiesen.

La idea principal era ofrecerles una manera de rescatar sus idiomas de la extinción.

En esta ponencia les contaré el proceso de desarrollo de aquel centro y nuestra intención de extender esta tarea a los pueblos indígenas de todo el mundo con la finalidad de preservar sus lenguas. Pero antes quiero explicarles porque debemos luchar para la preservación de la heterogeneidad lingüística.

\section{EL PROBLEMA}

En el año 1500, época en la que Cristóbal Colón llegó a las Américas, se hablaban alrededor de 7.000 lenguas en el mundo. Hoy, son cerca de 6.000. De ellas, sólo 276 son habladas por más de un millón de personas. Es decir, aproximadamente el $90 \%$ de todas las lenguas son habladas por indígenas

"CUADERNOS DE ESTUDIOS GALLEGOS", Tomo XL, Fascículo 105, Santiago 1992. 
como los Apaches en los E.E.U.U., los Samoanos en el Pacífico del Sur, los Jívaros en la jungla del Ecuador, en Papua Nueva Guinea, Africa, Asia, etc.

Si a esta población indígena la comparamos con la población total del planeta, sólo constituyen el 10\% de la población mundial. ¡Piénsenlo!: el 90\% de la población de la Tierra habla el 10\% de todas las lenguas existentes. En otras palabras, el $90 \%$ de las diferentes culturas y lenguas de todo el mundo constituyen el 10\% de la población mundial.

Sólo unas pocas comunidades linguísticas son relativamente grandes, como los Aymara (tres millones) en Bolivia y los Tswanas en Botswana (doce millones). Pero la malloría de ellas son más reducidas y por lo tanto frágiles, y cada año desaparecen más lenguas. Al ritmo en el que se extinguen hoy algunas lenguas, calculo que en el transcurso de 100 años sólo existirán unas 4.000.

Como antropólogo me asusta esta posibilidad. No es que apoye la diversidad cultural por si misma, ni la quiera preservar por piedad. Tampoco quiero preservar culturas raras y pintorescas por el placer de examinarlas. Me preocupa mas bien la propia humanidad; que la especie Homo Sapiens pueda estar expuesta a un riesgo evolutivo. La desaparición de la mayoría de las lenguas y culturas puede poner en juego la mera supervivencia como especie en el gran esquema de la naturaleza. Digo, que la puede poner en juego porque no tengo modo alguno de comprobar este presentimiento. Reflexionen sobre esto: hace 40.000 años sólo unos cuantos millones de seres humanos poblaban Africa, Asia y Europa. Hoy en día, somos más de cinco mil millones y hemos ocupado las Américas, las pequeñas islas del Pacífico, Australia, Nueva Zelanda. Nos hemos adaptado a las junglas, a los desiertos, a las tierras septentrionales e incluso a la zona ártica. Empleando cualquier medida razonable y en términos evolutivos, la especie $\mathrm{H}$. sapiens es una historia de éxito adaptativo.

En la antropología, es practicamente un artículo de fe que el éxito en la adaptación de nuestra especie fue gracias a la cultura, y no gracias a cambios físicos. Es decir, cuando el hombre se extendió a tierras frias, no le crecieron los pelos sino que el hombre utilizó las pieles y los pelos de otros animales.

El hombre, como animal, es bastante limitado: no vuela, no tiene zarpas y en comparación con otros animales, como la pantera o el gorila, es lento y débil. Pero el H. sapiens es el amo de la Tierra en razón a su capacidad cultural. Con el telescopio, el hombre, ve mejor que el águila; con sus armas, es más feroz que el león: con sus coches, es más rápido que la pantera. Su capacidad para la cultura le permite señorear.

"CUADERNOS DE ESTUDIOS GALLEGOS", Tomo XL, Fascículo 105, Santiago 1992. 
La cultura implica ideas y la comunicación de esas ideas por medio de la lengua. Pero la lengua no es sólo un vehículo para la comunicación de ideas; es la fuente de las ideas, y por lo tanto, la diversidad de lenguas es la fuente de ideas diversas para la adaptación -ideas sobre cómo transferir propiedad (y la idea misma de la propiedad personal), sobre la curación de enfermedades, sobre cómo adquirir alimentos, cómo criar niños, cómo distribuir el poder y cómo solucionar disputas.

Razonando así, cualquier reducción de la diversidad lingüística va a restringir el poder de adaptación de la especie H. sapiens. Imponer la homogeneidad lingüística puede ofrecer, a corto plazo, ventaja política o económica para una u otra cultura o para una clase social. Pero a largo plazo, a nivel de la especie humana y no a nivel de la cultura o una clase, el efecto de la homogeneización de culturas puede ser desastroso.

Estamos dirigiendo un experimento imprudente (yo diría, atolondrado) para ver cuáles son los efectos sobre la humanidad si eliminamos las especies culturales del mundo. Es imprudente porque si no nos gustan los resultados del experimento, no hay manera de dar marcha atrás.

\section{LAS LENGUAS INDIGENAS PERMANECEN AGRAFAS}

Antes del s. XVI saber leer era una destreza muy rara. Es cierto que nuestra civilización occidental disponía del alfabeto como instrumento cultural, posibilitando la capacidad de leer y escribir libros. Pero durante la Edad Antigua y Edad Media, sólo unos pocos miembros de nuestra cultura occidental sabían leer. Había que disponer de una pequeña fortuna para poseer un sólo libro, aunque entre los ricos no fuese necesario leer. En aquel entonces, cada ejemplar de un libro tenía que ser copiado a mano, encareciéndolo enormemente.

Desde el tiempo de Johannes Gütemberg, y con el perfeccionamiento de la imprenta, la producción en serie de libros ha disminuido los costos de los mismos y la posibilidad de leer y escribir se ha extendido en todas las partes de la Tierra. Estamos todavía en esta revolución y 500 años después de Gütemberg la gran mayoría de los idiomas del mundo permanecen ágrafos, sin tradición literaria y sin libros. No es por una ausencia de alfabetos. Casi todos los idiomas indígenas poseen alfabetos, confeccionados por misioneros y lingüistas durante los últimos 500 años. Y es una pequeña exageración afirmar que las lenguas indígenas del mundo no tienen un sólo libro. De

"CUADERNOS DE ESTUdIOS GALLEGOS", Tomo XL, Fascículo 105, Santiago 1992. 
hecho, muchos tienen tres: un texto de la gramática, un diccionario, y una Biblia, todos ellos escritos o traducidos por los mismos misioneros y lingüistas que construyeron los alfabetos.

Lo que estas lenguas no tienen es autores nativos que escriban libros en sus propios idiomas. Carecen del alfabetismo casual. Los hombres y mujeres que son casualmente alfabetizados leen periódicos y se cartean entre ellos como algo natural. Sin el alfabetismo casual, las lenguas indígenas del mundo desaparecerían. Y cuando una lengua ágrafa desaparece, se desvanece para siempre.

$\mathrm{Si}$, hay programas de educación bilingue. En estos programas los niños indígenas aprenden a leer y escribir en dos lenguas, en su lengua materna y en la lengua oficial de su país. En Africa, América Latina, América del Norte, Asia, y en las islas del Pacífico, los gobiernos gastan millones de dólares anualmente en dichos programas. En México, hay 56 lenguas indígenas habladas por unos diez millones de personas. Y hay programas en educación bilingue (lengua indígena y español) en la mitad de ellas. En Canadá existen 70 lenguas indígenas y programas bilingues de alfabetismo entre la mayoría (Cree, Ojibwa, Montagnais, Inuit (la lengua de los esquimos)), etc. En Estados Unidos, permanecen todavía 38 lenguas indígenas habladas cada una de ellas por más de mil personas y muchas reservas cuentan con programas de educación bilingue.

Pero estos programas no producen el alfabetismo casual. Habitualmente los niños aprenden a leer sus cartillas en la escuela, y en los programas apoyados por alguna iglesia pueden leer la Biblia. Estos niños invierten miles de horas de su niñez componiendo frases sencillas escritas en sus propias lenguas pero no llegan a escribir libros en sus propios idiomas. Los programas de educación bilingue no generan una verdadera literatura porque, con unas raras excepciones, no producen libros.

\section{¿POR QUE LAS LENGUAS INDIGENAS QUEDAN AGRAFAS?}

Hay cuatro posibles causas que expliquen el fracaso de los programas de educación bilingue:

1) Muchos hablantes de lenguas ágrafas creen que deben abandonar el habla de su lengua. Creen que así -no hablando su lengua en casa- obtendrán para sus hijos alguna ventaja económica. Razonan que una lengua minoritaria puede disminuir las posibilidades de obtener un empleo en el marco de

"CUADERNOS DE ESTUdIOS GALLEGOS", Tomo XL, Fascículo 105, Santiago 1992. 
la economía nacional.

Por un lado, tienen razón. En casi todas las partes, los indígenas están discriminados y no tienen las mismas oportunidades económicas que aquellos que están integrados en la cultura oficial de su país. Pero, también es verdad, abandonando la lengua indígena no obtienen ninguna ventaja económica. Hablaré ampliamente de este tema más adelante.

2) En algunos casos existen propuestas de alfabetos contrapuestos. La gente discute, argumenta y debate sobre cuál es el alfabeto más apropiado. Los diferentes alfabetos son frecuentemente el resultado de los esfuerzos de varios misioneros de diferentes ordenes que compiten por la lealtad y fidelidad de la gente.

3) Aun, en el caso de que haya un sólo alfabeto, éste puede ser demasiado complejo. He visto alfabetos tan difíciles de manejar que agotan los esfuerzos de aquellos que quieren escribir libros en su lengua.

Este problema es particularmente común en alfabetos creados para escribir lenguas tonales. En estos idiomas el tono es fonémico, es decir, cambia el sentido de la palabra. La palabra $b a$ pueden significar caballo, o arroz o el pasado del verbo cantar, dependiendo del tono (alto, bajo o zambullido). Cientos de lenguas tienen tres tonos. Algunas, como el Chananteco y el Amuzgo de México tienen seis tonos.

Los extranjeros, como misioneros y lingüistas, encuentran los idiomas tonales imposibles de leer si los tonos no están indicados. Construyen alfabetos engorrosos y pesados exigiendo que los tonos deban marcarse. Luego, convencen a la gente indígena que su lengua (previamente ágrafa) no se puede escribir correctamente si no se marcan los tonos.

Hablantes nativos de lenguas tonales no necesitan normalmente ver los tonos marcados en la escritura de sus lenguas. Perciben y entienden los tonos correctos en el contexto. Consideremos la frase: el muchacho [casa] [capa] [calla] [caza] [cava] el foso. Supongan que tuvieran que elegir una de las palabras entre corchetes. Ningún hablante nativo de castellano fracasaría en esta prueba. De igual manera, los hablantes nativos de lenguas tonales eligen la palabra correcta por el contexto de la frase.

Por supuesto podríamos idear ejemplos más ambiguos como: el muchacho [caza] [cava]. Pero son raras las ocasiones en las que uno tiene que elegir entre opciones tan ambiguas en frases tan aisladas. Las frases, como los pensamientos, surgen (vienen a la imaginación) en un contexto. Al fin y al cabo, si las frases ambiguas causan problemas de vez en cuando, este es un pequeño precio que hay pagar por la habilidad de leer y escribir. En mi expe-

"CUADERNOS DE ESTUDIOS GALLEGOS", Tomo XL, Fascículo 105, Santiago 1992. 
riencia, si se obliga a los indígenas a escribir en sus lenguas con los tonos marcados, simplemente no escriben. Volveré también sobre este tema más adelante.

4) Cuesta demasiado editar libros. A pesar de todos los problemas anteriores, hay indígenas que quieren escribir libros. Algunos -los he conocido personalmente- han escrito textos, bastante largos, a mano. Estos textos quedan inéditos porque los costos de la tecnología para imprimirlos son altos.

Si por ejemplo un hablante de Mixteco, en México, escribiera un manuscrito en su propia lengua, ninguna editorial comercial podría publicarlo. No les sería rentable. Requeriría un nuevo equipo de tipos de imprenta que ya han desaparecido. Si quisieran fabricar los nuevos caracteres (algo que es muy caro), no podrían componer los tipos, porque ningún empleado de editorial sabría colocar correctamente las palabras. Habría miles de errores tipográficos y su corrección requeriría miles de horas de trabajo suplementario (más gastos).

Los hablantes de Mixteco son alrededor de 300.000. Si se resolvieran todos los obstáculos para componer un libro, una tirada real de un libro en Mixteco podrían ser 300 copias. Con unas 150 páginas impresas y una encuadernación sencilla, el costo por cada ejemplar rondaría los 21.000 pesos mexicanos en 1990, o 700 pesetas españolas -fuera del alcance de casi todos los Mixtecos-. Y este sería el costo después de componer los tipos. Si incluyesemos todos los gastos, como debe ser, el costo de cada ejemplar alcanzaría las 1200 pts.

\section{LA MICROCOMPUTADORA Y LA ALFABETIZACION DE LOS INDIGENAS}

Llegamos a la microcomputadora. A comienzos de 1971, enseñaba al maestro Jesús Salinas Pedraza, un indio Otomi del estado de Hidalgo (México), a leer y escribir su propio idioma. Utilizábamos la versión modificada de un alfabeto que unos misioneros habían desarrollado con anterioridad.

Durante la década de los 70, con el apoyo de la Fundación Nacional de Ciencias y la Fundación Nacional de Humanidades de los Estados Unidos, Salinas escribía una descripción de su propia cultura, la cultura Otomi. Tradujo y mecanografió todo el texto en una computadora. De este proyecto resultaron dos libros: un volumen de cuentos folklóricos y un volumen sobre etnografía de los Otomi. Desafortunadamente, el alfabeto que utilizamos

"CUADERNOS DE ESTUDIOS GALLEGOS", Tomo XL, Fascículo 105, Santiago 1992. 
contenía algunos símbolos que no aparecían en el teclado normal de IBM. Por ejemplo, la letra $a$ suena algo como el sonido $a w$ en inglés. Se escribe en el alfabeto fonético internacional con un símbolo que semeja a una $c$ al revés. Como la letra $c$ no se utiliza en Otomi, se usaba para representar el sonido $a w$.

El problema fue que a los Otomi no le gustaron las adaptaciones y que a mi juicio resultaban muy fáciles; después de todo, todos los alfabetos son arbitrarios. Imaginaba que los Otomi podrían utilizar con facilidad cualquier letra disponible del teclado IBM para representar los sonidos de su lengua. Me sentía en cierto modo molesto cuando Salinas y otros maestros Otomis se mostraban reticentes y negaban el uso de los símbolos disponibles en el teclado estandar IBM.

Insistí a que ajustasen sus necesidades a la tecnología. Pero ellos exigían en cambio que la tecnología debería servir a sus necesidades y no al contrario. Tenían toda la razón.

En 1981 los procesadores de textos no estaban todavía lo sufientemente desarrollados. Casi nadie los utilizaba para escribir español o francés y mucho menos los idiomas exóticos ágrafos. Había un programa en cambio que era diferente. Se llamaba Gütemberg y había sido confeccionado por un editor profesional que veía la posibilidad de simular con el viejo Apple II a una máquina de prensa.

El Apple II disponía de lo que llamamos gráficas interponibles, o mediables de la pantalla; es decir, se pueden formular caracteres nuevos sobre la pantalla y reproducirlos en la impresora. El programa Gütemberg, que ahora resulta anticuado, disponía de su propio sistema para controlar el formato de la página y tenía la capacidad de recibir tipos múltiples, tenía pues la capacidad de los procesadores más avanzados en 1990, aunque más difíciles de manejar. Con este equipo, el viejo Apple y el programa Gütemberg, fue posible, no sin esfuerzo, tener durante los primeros años de la revolución del procesador una editorial sobre la mesa de un despacho.

Se diseñó pues un procesador de palabras Otomi y Salinas aprendió a manejarlo. Pude así cubrir (honrar) las necesidades de los Otomi para construir los caracteres y de este modo Salinas pudo escribir con el procesador de palabras Otomi una etnografía de más de 250.000 palabras. La traducción al inglés de esta monografía apareció en 1989. Desafortunadamente, aunque teníamos la traducción en español, las editoriales mexicanas no estuvieron interesadas en imprimir y difundir esta obra (heróica) de Salinas. Paradójicamente, pese a la proximidad del V Centenario de Colón, el interés 
por la preservación de las culturas indígenas en México era todavía superficial.

No puedo resaltar suficientemente la importancia que tiene en 1981 el poder producir sobre la pantalla los caracteres del alfabeto Otomi. Supongan que quieren crear el carácter $u$ subrayado. No existe hasta la fecha en ASCII el juego de símbolos internacionales disponibles para la computación. No obstante, con cualquier procesador de palabras uno podía construir ese carácter en $1981 \ldots$ pero solamente en la impresora y no en la pantalla.

En primer lugar, se creó un macro es decir, un juego de instrucciones que, al teclear la letra $u$, produce $u \$ \#$ en la pantalla. Segundo, se definió el carácter \$como un espacio atrás. Y finalmente, se definió el símbolo\# como subrayado. Durante el proceso de impresión este macro se interpretaría como una $u$ subrayada.

Es un sistema que realmente funciona aunque resulta feo estéticamente. Es tan antiestético que la gente no lo usa si no es preciso.

Durante varios años, los primeros procesadores americanos requerían de este engorroso truco para las impresoras de español y francés. Con el viejo equipo Apple II y el programa Gütemberg, Salinas pudo escribir los caracteres Otomies directamente en la pantalla en 1981.En 1984, Salinas tenía tanta destreza en escribir Otomi por computadora que me impulsó a reflexionar acerca de cómo podríamos extender el uso de la tecnología a otros grupos.

\section{EXTENDIENDO LA TECNOLOGIA A OTROS GRUPOS EN MEXICO}

Y así es como llegamos en 1987 a desarrollar un programa en un centro en el que los indios mexicanos pudieran aprender a leer y a escribir sus propias lenguas, y publicar sus obras utilizando microcomputadoras. El centro está apadrinado por cuatro organismos: La Dirección general de Educación Indígena de México, El Instituto Indigenista Interamericano, el Centro de Investigaciones y Estudios Superiores en Antropología Social (C.I.E.S.A.S.) y el Departamento de Antropología de La Universidad de Florida.

El C.E.L.E. (Centro Editorial en Lenguas Indígenas) se inició en Agosto de 1988 en la oficina principal del C.I.E.S.A.S. en Oaxaca ', capital del

${ }^{1}$ El Estado de Oaxaca es muy apropiado para la ubicación del centro, pues más de un millón de habitantes distrubuidos en siete familias hablan más de cien idiomas diferentes.

"CUADERNOS DE ESTUDIOS GALLEGOS", Tomo XL, Fascículo 105, Santiago 1992. 
estado de Oxaca (México). El Director del C.I.E.S.A.S.-Oaxaca es Salomón Nahmad Sitton, uno de los antropólogos más conocidos en México. En 1989, el C.E.L.I. recibió una subvención de la Fundación Jessie Ball du Pont, y la compañía Apple Computer donó los computadores. Salinas y la maestra Josefa Gonzalez Ventura, una mixteca de la costa de Oaxaca, son los responsables del centro.

Los indios pasan un período de formación de tres meses en el centro. Los entrenados son maestros bilingues del sistema nacional de educación. Ya saben leer y escribir español, por supuesto, y así no deben hacer mas que transferir la tecnología del alfabetismo para crear documentos en sus lenguas autóctonas. Lo encuentran muy fácil una vez que aprenden a manejar un procesador de palabras que contiene los caracteres que necesitan en su lengua particular. Es decir, los mixtecos aprenden a manejar un procesador Mixteco-Español; los Chinantecos aprenden con un procesador ChinantecoEspañol; etc. Durante su estancia en C.E.L.I.L., los maestros indígenas producen una obra amplia sobre el tema que ellos eligan y la publican para difundirla entre su propia gente.

Hasta la fecha, el centro de alfabetismo indígena en Oaxaca cuenta con un software obsoleto Gütemberg y los viejos Apples, pero empezamos este año a introducir equipos más modernos con impresoras laser, etc. A todos les gustan los nuevos equipos, pero la conclusión más importante de esta historia es que estas mejoras son sólamente maquillajes y sólo facilitan el uso de los equipos; pero no son indispensables. Hemos comprobado que la gente más humilde puede producir obras de suma belleza (poesía, cuentos, historias, descripciones etnográficas, etc.) con equipos de computación básicos y baratos.

Hasta el momento, han salido del centro 36 personas capacitadas y representan a siete lenguas mayores. Han producido lfbros en Otomi, Mixteco, Amuzgo, Chinanteco y Mazateco. Otros libros en Tzotzil y Zapoteco están en proceso. Un indio Shwara (Jivaro) de Ecuador pasó tres semanas en el centro y produjo un libro en Quichua. Regresó a su tierra con su equipo de computación y está estableciendo un nuevo centro entre su propia gente.

En la etapa siguiente, que ya se va a iniciar en Febrero, los autoresmaestros usarán sus libros en sus pueblos para enseñar lectura tanto a los adultos como a los niños. No existe un esfuerzo más potente para la alfabetización que un autor desee que otros lean su obra. 


\section{EXTENDIENDO LA TECNOLOGIA A AFRICA}

En Julio de 1988, Salinas y yo presentamos una muestra de nuestro trabajo al Congreso Internacional de Antropología, en Zagreb (Yugoslavia). El Dr. Paul Nchoji Nkwi, jefe de Antropología en la Universidad de Yaounde en Camerún, nos sugirió que la tecnología podría utilizarse para ayudar a la gente Kom de Camerún a escribir libros en su idioma. El Kom lo hablan 127.000 personas en Camerún y el Dr. Nkwi es un hombre Kom.

Nkwi y yo solicitamos una subvención a la Fundación Wenner-Gren y afortunadamente en Agosto de 1989 viajaba a Yaounde para enseñar a cinco hablantes Kom a utilizar una microcomputadora y un procesador de palabras en Kom.

El grupo de cinco estaba compuesto por dos maestros bilingues KomInglés, un maestro y una maestra; un joven abogado recién graduado en la Universidad de Yaounde; un estudiante de antropología; y un cura católico: El reino matrilineal Kom forma parte de un área que anteriormente había estado controlada por Inglaterra. Consecuentemente todos los Kom son bilingues de Inglés y Kom, y además saben escribir y leer inglés. Los Kom podrían leer libros en Kom si estos libros existieran.

Como la mayoría de las lenguas ágrafas, su ortografía está poco desarrollada. Tienen un alfabeto, pero carecen de las reglas codificadas para la escritura. La ortografía del español, por contra, consiste en un alfabeto y en un extenso cuerpo de reglas para el deletreo de las palabras, de la puntuación, para las sílabas, etc. Todas estas reglas ortográficas han emergido de la abundante literatura en español. Para captar lo importante y amplio que es el juego de reglas ortográficas para la escritura del español, piensen en el peso y el tamaño del diccionario de la Real Academia de la Lengua en donde estas reglas están compendiadas. Y esto es para el español de España. Además, hay reglas para los diferentes dialectos del español, el mexicano, el puertorriqueño, el ladino, etc. Por ejemplo, en México, escribimos el nombre de la república con $\mathrm{x}$, mientras en otros dialectos usan la j. De hecho, los convencionalismos para la escritura y la puntuación cambian dentro de un país a través del tiempo. Los autores se toman libertades con una u otra regla y el público acepta o rechaza los cambios. En México iniciamos la palabra sicología con s mientras que en otros dialectos del español mantienen la p inicial no pronunciada. Los libros editados en México hace 50 años demuestran que este cambio es reciente.

Sin embargo, la parte básica de cualquier ortografía es el alfabeto. El

"CUADERNOS DE ESTUDIOS GALLEGOS", Tomo XL, Fascículo 105, Santiago 1992. 
primer alfabeto para el idioma Kom fue creado por los misioneros alemanes en la década de los 80 del siglo XIX. Otros grupos religiosos contribuyeron en los siguientes cien años a la evolución del alfabeto tal y como hoy se conoce.

Los cinco miembros del proyecto Kom se familiarizaron con este alfabeto, pero ninguno de ellos había escrito un texto empleándolo substancialmente. Como eran buenos escritores en inglés, la tarea principal consistió en transferir esta habilidad a la escritura Kom, pero empleando el alfabeto que ya conocían.

Inmediatamente nos encontramos con un problema. El Kom es un idioma tonal, con tres tonos. Como indiqué anteriormente, los hablantes nativos de lenguas tonales no deben ver escritos los tonos para leer un texto. Los hispanófonos se quejan cuando estudian la escritura inglesa: cómo podemos saber en donde enfatizar una palabra; ¿cuándo hay acentos? Los anglófonos sí, tienen problemas con esto cuando son niños, pero los adultos ya no tienen necesidad de ver el acento marcado cuando leen. Lo saben por experiencia, y si encuentran una palabra que no entienden, y por lo tanto no saben como pronunciarla, consultan el diccionario. Allí encontrarán la palabra recogida en sílabas y con el acento marcado.

Habitualmente el español es conocido como un idioma racional en cuanto a su sistema de escritura. En su mayoría, las cinco vocales [a, e, i, o, u] representan solamente cinco sonidos, un sonido por cada vocal, y los acentos en español indican al lector en donde debe enfatizar las palabras que no tienen un énfasis predicho por cualquiera de las reglas.

Las palabras que terminan en $r$, por ejemplo, se enfatizan habitualmente en la sílaba final. No hay necesidad de marcar el énfasis con un acento excepto en los casos en los que no se cumpla la regla.

Bien, el no emplear acentos en español ofrecería una tremenda ventaja a los escritores y editores de libros españoles. Sin embargo, no encuentro ningún movimiento para rechazar el uso de los acentos en castellano. Está claro que los español-parlantes no necesitan ver representados los acentos para leer un texto con fluidez. Hispanófonos de todo el mundo que se comunican a través del correo electrónico escriben sin acentos, porque el teclado de la computadora carece de esta tecla (no sostiene el uso de acentos).

Los integrantes del proyecto Kom en Camerún aprendieron en la escuela cuando deberían marcar los tonos en Kom si querían que otros hablantes de Kom les entendieran. Yo programé un grupo de caracteres que incluían todas las vocales con sus tonos, y enseñé a los participantes como tenían que

"CUADERNOS DE ESTUDIOS GALLEGOS", Tomo XL, Fascículo 105, Santiago 1992. 
mecanografiar estos signos en la computadora. Lo cierto fue que el sistema resultó torpe y engorroso.

Cada sonido requería su propio carácter. Por ejemplo, si el sonido $a$ puede pronunciarse alto, medio, y zambullido, un teclado necesitaría para representar estas variantes tres caracteres diferentes: a a a. Multipliquen esto por siete vocales en Kom, y perciben la dificultad. Para mecanografiar el Kom con un teclado de computadora, hay que aprender a localizar ventiuna teclas especiales, y la gran mayoría de ellas serán difíciles de encontrar (tales como Shift Control i, por ejemplo).

Al tercer día, los cinco participantes Kom habían desestimado marcar los tonos. Uno de los maestros bilingues (maestro de primaria) exigía que los tonos deberían marcarse: es decir, creía que marcarlos era más correcto. No existe ningún argumento en contra de esta postura, así como no hay argumentos en contra de mantener los acentos en español. La tradición es su propia explicación y tiene que respetarse. Pero el hecho es que, al catorceavo día estos cinco hablantes de Kom habían generado un cuerpo de 25.000 palabras de literatura casual, adulta y literaria en Kom.

Era literatura casual: al final de las dos semanas, cada participante encendía su computadora a las ocho de la mañana y comenzaba a escribir sin titubeo, sin vacilación. Cualquier cosa que podía contar, la escribía.

Era literatura adulta: no contenía aquellas frases que uno observa en las cartillas de primaria (Pablo se va a la milpa para sembrar maíz); estaba compuesta de frases complejas.

Era literatura: no era un cuerpo de frases inconexas, como las frases que encontramos en las cartillas de alfabetización. Era un Kom fluido, textos de páginas y páginas sobre temas concretos y complicados. El abogado, por ejemplo, escribió sobre los contratos de boda Kom tradicionales; el cura escribió sobre el sincretismo de la religión indígena Kom con el catolicismo. Esta literatura Kom tiene algo que decir, y lo dice en términos explícitos.

Cada integrante leía los textos de sus compañeros, y al final clausuramos formalmente el programa (taller) con una ceremonia y una comida. Los participantes y mi colega Nkwi invitaron a unas de las 25 personas más importantes del reino Kom que residían en Yaounde. El cura redactó un discurso en Kom, sin ningún tono marcado, en el que describía las experiencias del grupo a lo largo de las dos semanas. La maestra lo pronuncia, en una locución fluida, después de haberlo leído una sóla vez.

La evidencia, pues, hasta ahora es que los Kom no necesitan marcar los tonos en su escritura, así como los anglófonos no deben marcar el énfasis

"CUADERNOS DE ESTUDIOS GALLEGOS", Tomo XL, Fascículo 105, Santiago 1992. 
para racionalizar su escritura. Podemos generalizar más aun y afirmar que el ser humano puede tolerar bastante ambiguedad en sus sistemas de escritura. Consideren que en Israel, el hebreo moderno se escribe sin vocales. Los inmigrantes recién llegados a Israel leen periódicos especiales con las vocales representadas; una vez que han aprendido a hablar, leer y escribir el hebreo suficiente, se graduan para leer los periódicos sin vocales y consideran que esto es un indicador de su asimilación a la moderna sociedad israelí.

Como había dicho anteriormente en México, el procesador de palabras facilitaba la comprobación de esta afirmación en Kom. También les facilitaba a los cinco participantes en el taller a desarrollar otras partes de su ortografía, más allá del alfabeto y de los tonos.

En un momento dado del programa, justifiqué un texto que uno de los integrantes había escrito, sólo para ver şu aspecto. Este truco les cautivó su imaginación y me solicitaron el aprenderlo. Por accidente, este truco les guió a desarrollar reglas de puntuación que de otra manera requeriría décadas para surgir.

La justificación de párrafos por procesador de palabras es muy atractiva pero en el caso de lenguas que usan muchas palabras largas (como alemán o griego) crea inevitablemente grandes y feos espacios en el texto.

La solución para estos espacios vacíos es el uso adecuado e inteligente del guión. Todos los que tienen experiencia en procesar palabras conocen la argucia. Uno justifica el texto al margen derecho y estudia los espacios en cada línea. Luego, decide a) si la línea tiene demasiados espacios y b) como romper, es decir, silabaficar y guionar la primera palabra de la línea siguiente. Así, una parte de dicha palabra se transfiere a la línea anterior y sus letras ocupan algunos de los espacios de dicha línea.

Los escritores Kom trabajan juntos para hacer estos ajustes. Discutían, línea por línea, como guionar algunas palabras. En algunos casos, concluyeron que algunas palabras largas eran realmente dos palabras diferentes, y no se deberían escribir juntas. Separaron estas palabras en lugar de guionarlas.

Tomando el desarrollo de la ortografía del español e inglés como escarmiento histórico, décadas y décadas de formular convenciones fueron compendiadas en unas pocas discusiones entre estos cinco pioneros sobre como guionar palabras en Kom para realizar un texto justificado lo más estético posible.

Esto nos conduce a un punto final sobre el uso de las computadoras en la preservación de las lenguas previamente ágrafas. Así como adquiere cual-

"CUADERNOS DE ESTUDIOS GALLEGOS", Tomo XL, Fascículo 105, Santiago 1992. 
quier lengua un cuerpo de literatura a través del tiempo, adquiere también la base para su diccionario. Las primeras ediciones de los famosos diccionarios de inglés, español, francés, fueron miniaturas en comparación con las ediciones actuales.

Llegaron a ser los monstruos que disfrutamos hoy porque las prensas de las naciones tecnológicamente más avanzadas han puesto en circulación inmensas cantidades de libros, periódicos, y otras formas de literatura durante los últimos doscientos años. Generaciones de creadores de diccionarios habían escudriñado y cribado este cuerpo voluminoso, en busca de nuevas palabras y nuevos usos y sentidos por palabras viejas, y anotando también cuando una palabra caía en desuso o se convertía en algo anticuado.

Consideren: un linguista trabajando diez años con indígenas produce un diccionario de 5.000 palabras. Hay todavía lenguas indígenas sin diccionarios. Pero el cuerpo de 25.000 palabras en Kom producido por estos cinco participantes en dos semanas contiene por lo menos 2.000 palabras únicas, y quizás hasta 4.000 . Ahora, podemos usar la computadora para aislar y extraer las palabras únicas en un texto, organizarlas en un orden alfabético, y presentarlas en la pantalla para el input de la información necesaria en un diccionario (el significado, el género, notas gramaticales, etc.).

\section{CONCLUSION}

1) El alfabetismo no necesariamente hace literatura. De hecho, en las primeras etapas del alfabetismo general de una sociedad es al revés. La literatura crea el alfabetismo.

Es decir, simplemente enseñando a la gente a leer y escribir no resulta que autores nativos escriban libros. Enseñando a unos cuantos muy motivados, por contra, y dándoles las herramientas no solamente para escribir sino también para editar y publicar libros, puede dar lugar a miles de alfabetizados. La gente lee cuando tiene algo interesante para leer -etnografías o biografías, manuales sobre como mejorar la cosecha de soja, novelas de romance.

Los participantes en los proyectos de Oaxaca y Yaunde escribieron sobre su propia cultura y sobre su ambiente, sobre cosas que interesaría leer a otros. Vale la pena repetir que los autores profesan mucho cariño a sus propias obras y tienen mucho interés en que las lea la gente, y están por ello motivados para enseñar a la gente a leer.

"CUADERNOS DE ESTUdIOS GALLEGOS", Tomo XL, Fascículo 105, Santiago 1992. 
2) Una razón importante de la ausencia de literatura casual entre los grupos indígenas es que no tienen acceso a los medios de producción de libros.

Los libros son comodidades como el café, el azúcar, el trigo. La tecnología normal para hacer libros es demasiado cara para la mayoría de la gente indígena. Los microcomputadores pueden eliminar este obstáculo.

Afirmo que la producción de literatura en estas lenguas previamente ágrafas preserva la diversidad linguíistica y cultural del planeta. Aún más, afirmo que está en nuestros propios intereses humanísticos apoyar esta actividad. Pensamos en nuestras lenguas, y pensamos diferentes pensamientos en nuestras diferentes lenguas. Desde mi punto de vista, nada menos que la riqueza del pensamiento humano está en juego. Pero afirmo más todavía. El preservar la heterogeneidad lingüística y cultural forma también parte de nuestros intereses materiales. En todas las partes del mundo hoy, la gente está reclamando medidas para la conservación de los recursos nacionales, del patrimonio nacional, y están defendiendo sus reclamaciones y sus derechos en términos de identidad cultural. Cualquier afirmación que un grupo cultural merezca reconocerse tiene más impacto, es más creible, cuando el grupo tiene su propio idioma.

Los hechos recientes en Armenia y en Yugoslavia muestran lo importante que es que los grupos étnicos retengan, guarden y conserven sus propios idiomas. Muestran también como la gente siempre define sus derechos políticos y económicos en términos de su identidad cultural; como la identidad cultural está definida en términos lingüísticos.

Consideren un caso reciente: un grupo de indígenas mexicanos presentaron un pleito contra una compañía de electricidad. La compañía había recibido el apoyo financiero de una agencia internacional de desarrollo para instalar un generador hidroeléctrico, que requería la previa construcción de una enorme presa en un río que cruzaba la tierra de los antepasados indios. La presa, si se construyera, iba a crear un lago inmenso que inundaría miles de hectáreas de estas tierras, tierras que los indios consideran hereditarias.

La compañía ofreció, por supuesto, pagar a los indios una indemnización en compensación por la pérdida de sus tierras.

El gobierno apelaba a los indios que aceptaran la oferta de la compañía. El gobierno indicaba su posición: era una obligación patriótica y los indios, como mexicanos, deberían aceptar la oferta de la compañía, y así contribuir al desarrollo de la nación.

Los indios sostenían otra posición: la oferta, argumentaban, era inade- 
cuada. Pero mas importante, dijeron, que querían conservar sus tierras para mantener su identidad. Los abogados de la compañía notaron que entre este grupo indígena había sólo unos cuantos muy viejos que hablaban la lengua del grupo, y que ningún joven la hablaba. Cómo, se preguntaban estos abogados, ¿pueden estos indios esperar convencer a alguien que merecen consideración especial a base de su estatus cultural cuando no hablan su propia lengua?. Cómo, de veras. ¿Cómo?.

\section{AGRADECIMIENTOS}

Este artículo se ha enriquecido gracias a los consejos de las siguientes personas: Georges Bedell, Kenneth Hale, Eric Hamp, Marvin Harris, Dell Hymes, Allan Lomax, Nancy Lurie, Duane Metzger, Salomón Nahmad, Jack Roberts, Scott Robinson, y Oswald Werner. Mis agradecimientos profundos a Jessie Ball du Pont Foundation, al Wenner Gren Foundation for Anthropological Research, y Apple Computer, Inc. por su apoyo. 